acceptable alternative to full dose treatment with bile acid for radiolucent gall stones, which is likely to offer added benefits in the shape of good control of symptoms and reduced costs.

We thank Rowa Ltd for supplies of Rowachol capsules and financial support of WRE during a research fellowship. We also thank Dr D H Rose and Dr D R Knapp for the ultrasound examinations and cholecystogram reports.

\footnotetext{
References

' Danzinger RG, Hofmann AF, Schoenfield LJ, et al. Dissolution of cholesterol gallstones by chenodeoxycholic acid. $N$ Engl $\mathscr{f}$ Med 1972;286:1-8. ell GD, Whitney B, Dowling RH. Gallstone dissolution in man using chenodeoxycholic acid. Lancet 1972;ii:1213-6.

Iser JH, Sali A. Chenodeoxycholic acid: a review of its pharmacological properties and therapeutic use. Drugs $1981 ; 21: 90-114$

acid in the treatment of cholesterol and $833-56$

cholelithiasis. Dig Dis Sci 1982;27:737-61 and 833-56. gallstones: the National Co-operative Gallstone Study. Ann Intern Med 1981; 95:257-82.

${ }^{6}$ Anonymous. Dissolving hopes for gallstone dissolution ? Lancet 1981 ;ii :905-6.

Mörsdorf K. Les terpènes cycliques et leur action choléretique. Bulletin de Chimie Therapeutique 1965;4:442-443.

Boettge K. Atherische Ole und Spasmolyse. Medizinische Monatsschrift 1954;8: 444-6.

Offergeld H. Basis of the therapy of the cholecystopathies. 55th medical congress, Berlin. Bantry: Rowa, 1952. Available on request from Rowa Ltd.

Sarreither W. Rowachol, ein terpenhaltiges Praparat zur Behandlung der

Greif S. Empirical report on Rowachol. Bantry: Rowa, 1956. Available on request Rowa Ltd.

Okabe $\mathrm{H}$. Clinical experience with terpene preparation (Rowachol) in treatment of disea

${ }^{13}$ Kameda $\mathrm{H}$. Clinical investigations of disease of the gallbladder and the biliary
}

ract, in particular the results of infra-red spectrophotometric examination. Naika Hokan 1960;6:3-15.

Noda H, Kuriyama S, Tokuda A. Clinicopathological studies on cholelithiasis II. Medical treatment of cholelithiasis-experience with terebene oil preparation. Naika Hokan 1965;12:505-11.

Hordinsky BZ. Terpenes in the treatment of gallstones. Minn Med 1971;54:649-52. Bell GD, Doran J. Gall stone dissolution in man using an essential oil preparation. Br Med F $1979 ;$; : 24

(ote bile acid treatment fo

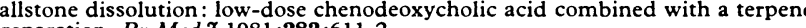
preparation. Br Med f 1981;282:611-2.

Bell GD, Clegg RJ, Ellis WR, et al. How does Rowachol, a mixture of plant monoterpenes, enhance the cholelitholytic potential of low and medium dos

omerville KW, Rose $\mathrm{DH}$, Bell GD, et al. Gallstone dissolution and recurrence: are we being misled ? Br Med f 1982;284:1295-7.

${ }^{20}$ Dowling RH. Medical treatment of gallstones with CDCA and UDCA. In: Paumgartner G, Stiehl A, Gerok W, eds. Bile acids and lipids. Lancaster: MTP

Press, 1981 :329-39.
Metropolitan Life Insurance Company. Statistical bulletin. New York: Metropoli-

tan Life Insurance Co, 1959.
Iser JH, Maton PN, Murphy GM, et al. Resistance to chenodeoxycholic acid (CDCA) treatment in obese patients with gallstones. Br Med F 1978; ; : 1509-12. gallstones. Gut 1979;20:312-7. Rowachol-a possible treatment for cholestero gallstones. Gut $1979 ; 20: 312-7$.

列 $1982 ; 2: 587-90$.

${ }^{25}$ Bateson MC, Ross PE, Murison J, et al. Comparison of fixed doses of chenodeoxycholic acid for gallstone dissolution. Lancet $1978 ; \mathrm{i}: 1111-4$.

${ }^{6}$ Gerolami A, Sarles H. Brette R, et al. Controlled trial of chenodeoxycholic acid therapy for radiolucent gallstones. Digestion 1977;16:299-307.

27 Toouli J, Jablonski P, Watts JMcK. Treatment of gallstones by chenodeoxycholic acid. Med F Aust 1980;1:478-9.

${ }^{8}$ Maudgal DP, Bird R, Northfield TC. Optimal timing of doses of chenic acid in patients with gallstones. $\mathrm{Br} M e d \mathcal{F}$ 1979;i:922-3.

Mok HYI, Bell GD, Dowling RH. Effect of different doses of chenodeoxycholic cid on bile lipid composition and on frequency of side effects in patients with gallstones. Lancet 1974 ;ii:253-7.

Thistle JL, Hofmann AF, Yu PYS, et al. Effect of varying doses of chenodeoxycholic acid on bile lipid and biliary bile acid composition in gallstone patient

a dose-response study. American fournal of Digestive Diseases 1972,22:1-6. pharmacokinetics and bioarilability of chenodeoxycholic acid. Eur 7 Clin Inves $1980 ; 10: 261-71$.

(Accepted 4 May 1984)

\title{
Effects of treatment for hypertension on cerebral haemorrhage and infarction
}

\author{
D G BLACK, A M HEAGERTY, R F BING, H THURSTON, J D SWALES
}

\begin{abstract}
One hundred and sixty nine patients admitted to hospital for stroke over 30 months were examined to see whether treating hypertension had influenced the incidence of cerebral haemorrhage and infarction. Seventy eight $(46 \%)$ of them had normal blood pressure, $47(28 \%)$ previously diagnosed hypertension for which they were receiving treatment, and $44(26 \%)$ previously undiagnosed and untreated hypertension. Haemorrhagic stroke was commoner among patients with untreated hypertension, whereas infarction was commoner in patients with treated hypertension. Infarction and haemorrhage were equally prevalent in patients with normal blood pressure.

Effective treatment in this population seemed to have had a substantially different impact on vascular disease,
\end{abstract}

\section{City Hospital, Nottingham}

D G BLACK, MB, senior house officer in medicine

Department of Medicine, Clinical Sciences Building, Leicester Royal Infirmary, PO Box 65, Leicester LE2 7LX

A M HEAGERTY, MB, MRCP, lecturer in medicine

R F BING, MB, MRCP, senior lecturer in medicine

H THURSTON, MD, FRCP, reader in medicine

J D SWALES, MD, FRCP, professor of medicine

Correspondence to: Dr A M Heagerty. giving rise to cerebral haemorrhage as opposed to infarction. This is consistent with evidence from other studies that treatment for hypertension has little or no effect on the progression of atheroma.

\section{Introduction}

Hypertension is the most important known cause of strokes in men and women of all ages. ${ }^{1}$ Despite a fall in the incidence of fatal strokes in some countries ${ }^{2}$ cerebrovascular disease still remains a major cause of death and disability, particularly among elderly people, though effective control of blood pressure has been confirmed to reduce the incidence of stroke in patients with moderate or severe hypertension ${ }^{3}$ and produce a dramatic improvement in prognosis among patients at highest risk.

Theoretically there could be two explanations for the continuing high incidence of strokes despite widespread availability of effective antihypertensive drugs. Strokes might be the result of untreated hypertension, or, alternatively, of hypertension for which treatment is, at least when started, partially or wholly ineffective. Epidemiological evidence suggests that hypertension remains an important treatable cause of death in the United Kingdom, ${ }^{5}$ and there can be little doubt that even patients at high risk go untreated. On the other hand, not all vascular pathological abnormalities associated with hypertension are reversed by control of blood pressure. Thus in most studies treatment for hypertension has had a disappointingly small effect on incidence of myocardial infarction. ${ }^{36}$ Strokes in patients 
with hypertension may be the result of haemorrhage from Charcot-Bouchard aneurysms or aneurysms of the circle of Willis. Alternatively, they may be due to infarction as a result of thrombotic or embolic blockage of a vessel, usually in association with atheroma. The effects of treatment may differ according to the nature of the lesion.

Strokes caused by haemorrhage or infarction can now be differentiated by computed tomography in patients who survive a stroke. Accordingly we assessed a group of patients admitted to hospital for acute stroke and related the underlying lesion to blood pressure to determine how far strokes might be associated, firstly, with untreated hypertension and, secondly, with the failure of treatment to influence sequelae of atheroma.

\section{Subjects and methods}

One hundred and sixty nine patients were admitted with strokes to the university department of medicine at Leicester Royal Infirmary over 30 months. Stroke was defined as the sudden onset of focal neurological symptoms that persisted for more than 24 hours. Patients with intracranial infections or primary or secondary cerebral tumours presenting with neurological symptoms were excluded from the study. Subjects were carefully assessed and assigned to one of three groups: patients with normal blood pressure, patients with hypertension for which they were receiving treatment, and patients with untreated hypertension. Measurements of blood pressure on admission are unreliable because blood pressure may be acutely raised as a result of the stroke and transfer to hospital. Diagnosis of hypertension was therefore based on a combination of findings: the medical history (from general practitioner or hospital records); a sustained blood pressure of over $160 / 95 \mathrm{~mm} \mathrm{Hg}$ during the period in hospital; evidence of cardiac hypertrophy on electrocardiogram or echocardiogram in the absence of outlet flow obstruction; and grade III or IV optic fundal changes on the Keith-Wagener scale.

The patients were investigated thoroughly to determine the nature of their stroke. Some died too soon or were deemed too ill for intensive testing, and, unless a postmortem examination was performed, we could not firmly classify their strokes. In the rest a classification was made. Cerebral haemorrhage was diagnosed by computed tomography, the finding of subhyaloid retinal haemorrhages, uniformly bloodstained cerebrospinal fluid, or findings at necropsy. Cerebral infarction was diagnosed if the computed tomogram showed the characteristic appearances of low density areas of infarction. All cerebral computed tomograms were done within five days after admission, and thus in some patients the signs of infarction were not apparent: in the absence of the appearance of blood, however, these patients were considered to have sustained infarction.

Statistical analysis was carried out by means of a $\%^{2}$ test and Student's $t$ test.

\section{Results}

Of the 169 patients studied, 78 were classified as having normal blood pressure and 91 as having hypertension (table I). The group with hypertension was subdivided into those receiving and those not receiving treatment. Mean ages and sex ratios were the same for the two main groups, and survival rates (defined as survival for at least four weeks from the day of admission) were also identical. For each

TABLE I-Characteristics of all 169 patients admitted with an acute stroke

\begin{tabular}{|c|c|c|c|}
\hline & \multirow{2}{*}{$\begin{array}{l}\text { Patients } \\
\text { with } \\
\text { normal } \\
\text { blood } \\
\text { pressure } \\
(\mathrm{n}=78)\end{array}$} & \multicolumn{2}{|c|}{$\begin{array}{l}\text { Patients with } \\
\text { hypertension }\end{array}$} \\
\hline & & $\begin{array}{c}\text { Receiving } \\
\text { treatment } \\
(\mathrm{n}=47)\end{array}$ & $\begin{array}{l}\text { Not receiving } \\
\text { treatment } \\
(\mathrm{n}=44)\end{array}$ \\
\hline $\begin{array}{l}\text { Mean (SEM) age (years) } \\
\text { No of men } \\
\text { No of women } \\
\text { Mean (SEM) blood pressure }(\mathrm{mm} \mathrm{Hg}) \text { :* }^{*}\end{array}$ & $\begin{array}{c}66(1 \cdot 6) \\
46 \\
32\end{array}$ & $\begin{array}{c}66(0 \cdot 9) \\
27 \\
20\end{array}$ & $\begin{array}{c}66(1 \cdot 1) \\
24 \\
20\end{array}$ \\
\hline $\begin{array}{l}\text { Systolic } \\
\text { Diastolic } \\
\text { No survived } \\
\text { No died }\end{array}$ & $\begin{array}{c}148(3 \cdot 1) \\
83(1 \cdot 9) \\
39 \\
39\end{array}$ & $\begin{array}{l}177(3 \cdot 5) \\
100(2 \cdot 3) \\
25 \\
22\end{array}$ & $\begin{array}{l}194(4 \cdot 8) \\
115(2 \cdot 7) \\
22 \\
22\end{array}$ \\
\hline
\end{tabular}

${ }^{*}$ Mean readings 24 hours after admission. group and for the overall series patients with cerebral infarction showed better survival rates than patients with cerebral haemorrhage ( $p<0.001$ for the whole group). Mean blood pressures on admission were higher in both untreated and treated patients with hypertension than in patients with normal blood pressure. Despite receiving antihypertensive treatment the treated group still had a raised mean blood pressure on admission compared with the group with normal blood pressure $(p<0.001)$, indicating that in some patients at least treatment had been less than optimal. The strokes of 126 patients were classified according to whether they resulted from a haemorrhage or infarction. By far the most useful method for determining this was computed tomography $(97(77 \%))$. Otherwise, haemorrhage was diagnosed in 13 by lumbar puncture. In 12 the diagnosis was made at necropsy, and in four by observing subhyaloid haemorrhages on fundoscopy.

Group with normal blood pressure-Of the 78 patients with normal blood pressure $28(36 \%)$ were classified as having had cerebral haemorrhage and $27(35 \%)$ as having had infarction. In $23(29 \%)$ the cause was not established (table II). Patients with haemorrhage were younger as a group (subarachnoid and intracerebral haemorrhage were equally common in this group). Ten of the 27 survived. Of them seven underwent cerebral angiography, which showed arterial aneurysms of the circle of Willis in three, atheromatous vessels only in three, and no lesions in one. All three patients with aneurysms underwent successful surgery. In 16 patients with cerebral infarction a possible cause was discovered: eight had atrial fibrillation or had recently suffered myocardial infarction, three had diabetes mellitus, two had atheromatous narrowing of their carotid arteries, one had hyperlipidaemia, one had a left ventricular aneurysm, and one was taking the oral contraceptive pill.

Group with treated hypertension-Only six $(13 \%)$ of these patients were found to have had a cerebral haemorrhage (table II), and again subarachnoid and intracranial haemorrhage were equally distributed. Compared with the group with normal blood pressure a significantly higher proportion of patients $(29(62 \%))$ had sustained cerebral infarctions $(p<0.01)$. Twelve patients had other conditions that increased their risk of sustaining an infarction: seven had atrial fibrillation or recent myocardial infarction, four had diabetes mellitus, and one atrial fibrillation and diabetes.

Group with untreated hypertension-The proportion of haemorrhage to infarction was reversed in this group with $23(52 \%)$ classified as having had haemorrhage and $13(30 \%)$ as having had infarction. Intracerebral haemorrhage was more than twice as common as subarachnoid haemorrhage (table II). The ratio of the incidence of cerebral haemorrhage to cerebral infarction was significantly different from the ratio in the group receiving treatment $(p<0.001)$. In 13 patients computed tomography showed the haemorrhage to have been intracerebral. Two patients subsequently underwent surgery after angiography showed aneurysms. One patient died from intracerebral haemorrhage and subdural haematoma after taking warfarin for a prosthetic heart valve. Three of the patients who had had cerebral infarction showed atrial fibrillation or had had a recent myocardial infarction.

$\varkappa^{2}$ analysis of the data afier subgrouping cerebral haemorrhages into subarachnoid or intracerebral lesions did not alter the findings (table III). The reduction in cerebral haemorrhage seen in the group with treated hypertension was due to a decrease in both subarachnoid and intracerebral haemorrhages. Moreover, in the group with untreated hypertension the increase in the incidence of cerebral haemorrhage was attributable to intracerebral rather than subarachnoid haemorrhage.

\section{Discussion}

We studied patients admitted to hospital with a stroke; the study therefore represents those with sufficient disability to warrant admission and excludes those who fail to survive the initial insult. This explains the greater incidence of haemorrhage in this study compared with community based studies. ${ }^{7}$ The results underline the importance of hype itension in the causation of strokes. ${ }^{1}$ The definition of hypertension $(>160 / 95 \mathrm{~mm} \mathrm{Hg})$ was based on criteria of the World Health Organisation and probably included patients with mild hypertension in whom the benefits of treatment are debatable. The Framingham study, however, showed that systolic blood pressure greater than $160 \mathrm{~mm} \mathrm{Hg}$ was associated with a doubling of the incidence of stroke, ${ }^{1}$ and in the Australian therapeutic trial in hypertension treatment of diastolic blood pressure in the range $95-109 \mathrm{~mm} \mathrm{Hg}$ 
reduced the incidence of stroke by nearly a half. ${ }^{8}$ The grossly raised blood pressures in our patients with untreated hypertension (table I) indicated that many of these patients belonged to a high risk group. This was supported by the need for treatment for hypertension in most survivors in this group. In view of the indisputable evidence that treatment reduces the incidence of stroke among such patients ${ }^{3}$ it is difficult to escape the conclusion that some strokes were avoidable.

The type of stroke was classified in $75 \%$ of our patients, the remainder being too ill to undergo intensive investigations (mortality was high in this group). Intracerebral haemorrhages were subdivided into subarachnoid or intracerebral lesions as the pathogenesis of the lesions is different. Whereas intracerebral bleeding is associated with rupture of Charcot-Bouchard aneurysms, subarachnoid lesions often arise from congenital berry aneurysms, although hypertension is believed to play a part in the development and rupture of such aneurysms. ${ }^{9}$ The distinction between subarachnoid and intracerebral lesions was made by postmortem examination, fundoscopy, or lumbar diagnosis and the need to confirm diagnosis at necropsy. ${ }^{10} 11$ The present observations indicate major differences between the incidence of infarction and haemorrhage in patients with normal blood pressure, patients with treated hypertension, and patients with untreated hypertension. Thus, though patients with treated hypertension sustained five times as many infarcts as haemorrhages, patients with untreated hypertension sustained twice as many haemorrhages as infarcts. The incidence of the two lesions was almost equal in the group with normal blood pressure. Our findings therefore support Pickering's suggestion that untreated hypertension is associated with an increased incidence of haemorrhagic stroke, at least in the case of a hospital based population. ${ }^{12}$ Likewise, treatment probably reduced the risk of a hypertensive patient sustaining a cerebral haemorrhage. The high incidence, however, of cerebral infarction in the treated group was greater than expected. Thus the beneficial effects of treatment for hypertension on strokes appears to be predominantly, if not entirely, due to a reduction in the risk of cerebral haemorrhage. The significant excess of cerebral

TABLE II-Characteristics of 169 patients according to type of stroke sustained

\begin{tabular}{|c|c|c|c|c|c|c|c|}
\hline & \multirow{2}{*}{$\begin{array}{c}\text { Mean }(\mathrm{SEM}) \\
\text { age (years) }\end{array}$} & \multirow[b]{2}{*}{ No of men } & \multirow[b]{2}{*}{ No of women } & \multicolumn{2}{|c|}{ Mean (SEM) blood pressure } & \multirow[b]{2}{*}{ No survived } & \multirow[b]{2}{*}{ No died } \\
\hline & & & & Systolic & Diastolic & & \\
\hline Heemorthag. & \multicolumn{7}{|c|}{ Patients with normal blood pressure $(n=78)$} \\
\hline $\begin{array}{l}\text { Haemorrhage: } \\
\text { Subarachnoid }(n=14) \\
\text { Intracerebral }(n=14) \\
\text { Infarction }(n=27) \\
\text { Unclassified }(n=23)\end{array}$ & $\begin{array}{l}57(4 \cdot 7) \\
65(3 \cdot 8) \\
65(1 \cdot 3) \\
75(0 \cdot 7)\end{array}$ & $\begin{array}{r}8 \\
8 \\
16 \\
14\end{array}$ & $\begin{array}{r}6 \\
6 \\
11 \\
9\end{array}$ & $\begin{array}{l}154(6 \cdot 7) \\
144(9 \cdot 3) \\
142(5 \cdot 0) \\
154(5 \cdot 5)\end{array}$ & $\begin{array}{l}85(3 \cdot 7) \\
81(3 \cdot 9) \\
79(3 \cdot 8) \\
88(3 \cdot 4)\end{array}$ & $\begin{array}{r}6 \\
2 \\
20 \\
9\end{array}$ & $\begin{array}{r}8 \\
12 \\
7 \\
14\end{array}$ \\
\hline Haemorrhage. & \multicolumn{7}{|c|}{ Patients with treated hypertension $(n=47)$} \\
\hline $\begin{array}{l}\text { Subarachnoid }(n=3) \\
\text { Intracerebral }(n=3) \\
\text { Infarction }(n=29) \\
\text { Unclassified }(n=12)\end{array}$ & $\begin{array}{l}60(7 \cdot 7) \\
65(5 \cdot 2) \\
65(0 \cdot 9) \\
70(0 \cdot 8)\end{array}$ & $\begin{array}{r}2 \\
18 \\
7\end{array}$ & $\begin{array}{r}3 \\
1 \\
11 \\
5\end{array}$ & $\begin{array}{l}183(3 \cdot 3) \\
167(12) \\
179(3 \cdot 9) \\
171(3 \cdot 6)\end{array}$ & $\begin{array}{l}110(15 \cdot 3) \\
90(5 \cdot 8) \\
102(2 \cdot 2) \\
92(2 \cdot 8)\end{array}$ & $\begin{array}{r}2 \\
21 \\
2\end{array}$ & $\begin{array}{r}3 \\
1 \\
8 \\
10\end{array}$ \\
\hline \multicolumn{8}{|c|}{ Patients with untreated hypertension $(n=44)$} \\
\hline $\begin{array}{l}\text { Haemorrhage: } \\
\text { Subarachnoid }(n=7) \\
\text { Intracerebral }(n=16) \\
\text { Infarction }(n=13) \\
\text { Unclassified }(n=8)\end{array}$ & $\begin{array}{l}68(3 \cdot 4) \\
61(3 \cdot 1) \\
64(1 \cdot 0) \\
74(1 \cdot 1)\end{array}$ & $\begin{array}{r}2 \\
11 \\
8 \\
4\end{array}$ & $\begin{array}{l}5 \\
5 \\
5 \\
4\end{array}$ & $\begin{array}{l}171(8 \cdot 0) \\
202(12 \cdot 9) \\
172(4 \cdot 6) \\
223(2 \cdot 7)\end{array}$ & $\begin{array}{l}101(5 \cdot 5) \\
121(6 \cdot 4) \\
106(2 \cdot 7) \\
127(2 \cdot 7)\end{array}$ & $\begin{array}{r}3 \\
6 \\
11 \\
2\end{array}$ & $\begin{array}{r}4 \\
10 \\
2 \\
6\end{array}$ \\
\hline
\end{tabular}

TABLE III-Results of $\chi^{2}$ analysis of distribution of types of stroke in patients with normal blood pressure, treated hypertension, or untreated hypertension. Figures show frequencies with expected frequencies in parentheses

\begin{tabular}{lcccc}
\hline & Subarachnoid & Intracerebral & Infarct & Unknown \\
\hline haemorrhage & haemorrhage & $14(15 \cdot 2)$ & $27(31 \cdot 8)$ & $23(19 \cdot 8)$ \\
Patients with normal blood pressure & $14(11 \cdot 1)$ & $3(9 \cdot 2)$ & $29(19 \cdot 2)$ & $12(12 \cdot 0)$ \\
Patients with treated hypertension & $3(6 \cdot 7)$ & $16(8 \cdot 8)$ & $13(18 \cdot 0)$ & $8(11 \cdot 2)$ \\
Patients with untreated hypertension & $7(6 \cdot 2)$ & & \\
\hline
\end{tabular}

puncture as computed tomography is unable to distinguish accurately between the two lesions. The analyses were, however, unaltered by exclusion of patients with subarachnoid haemorrhage (table III).

Only in a few patients could strokes not be classified. In some cases this was because a scanner for computed tomography was temporarily unavailable. In other cases, however, the patient was too ill to undergo investigation; this group showed a lower rate of survival. In such patients cerebral haemorrhage was probably the most common lesion. Even if, however, all the unclassified patients were said to have had cerebral haemorrhage, cerebral infarction would still predominate substantially in the treated group and cerebral haemorrhage in the untreated group (table II).

In classifying our patients into those with hypertension and those with normal blood pressure we almost certainly misclassified some patients for whom previous records were not available, but this probably did not introduce a major systematic error into the data. Previous studies of the incidence of cerebral infarction and haemorrhage among patients admitted to hospital for stroke have been constrained by the limitations of clinical infarction in the group with treated hypertension compared with the group with normal blood pressure cannot be interpreted as indicating that drug treatment has an adverse effect on this condition. Severe degrees of atheroma are likely to be present in a population with longstanding hypertension, even if such patients are treated, and this population will therefore be predisposed to cerebral infarction. Although over zealous lowering of blood pressure may produce cerebral infarction in patients with hypertension, ${ }^{13}$ this usually occurs with parenteral treatment and usually shortly after its start. ${ }^{14}$ In our patients with treated hypertension there was no evidence that the infarction occurred shortly after beginning treatment. Even so, survival was better in the patients with infarction than in those with cerebral haemorrhage.

These findings are consistent with reports indicating that antihypertensive treatment has little effect on another condition usually resulting from atheroma-namely, ischaemic heart disease. ${ }^{36}$ In our study, though there was no direct evidence that cerebral infarction was caused by atheroma, this was likely to have been the case in most patients. Even when patients with other possible causes such as embolism are excluded the relation 
between infarction and haemorrhage in the three groups is essentially unchanged.

That treatment has different effects on different lesions caused by hypertension is perhaps not surprising. The most probable explanation is that the processes giving rise to atheroma are already established at the time when treatment is begun and that progression of these processes is unaffected by treatment. If so, preventive methods may require earlier intervention even before drug treatment would normally be considered. Further studies of possible reversible environmental factors in hypertension are required to define how practicable such measures are, but the burden of cerebrovascular disease in an aging population demands that these problems be examined scientifically.

\section{References}

' Kannel WB, Wolf PA, Veter J, McNamara PM. Epidemiological assessment of the role of blood pressure in stroke. The Framingham Study. $\mathcal{F} A M A$ 1970; 214:301-10.
" Garraway WM, Whistant JP, Furlam AJ, Phillips LH, Kurland LT, O'Fallon WM. The declining incidence of stroke. N Engl 7 Med 1979;300:449-52.

Veterans Administration Study on Hypertensive Agents. Effect of treatment on 政 averaging 115 through $129 \mathrm{~mm} \mathrm{Hg}$. $\mathcal{F} A M A$ 1967;202:1028-34.

' Swales JD, Bing RF, Heagerty A, Pohl JEF, Russell GI, Thurston $H$. Treatment of refractory hypertension. Lancet $1982 ;$; :894-6.

Charlton JRH, Hartley RM, Silver R, Holland WW. Geographical variation in 1983;i:691-6. changes in life expe Oxford Community Stroke Project. Incidence of stroke in Oxfordshire: first year's experience of a community stroke register. Br Med f 1983;287:713-6.

s Australian Therapeutic Trial in Mild Hypertension. Report by the management

- Harrison MJG. Hypertension and Stroke. Br f Hosp Med 1984;31:215-8.

Aring CD, Merritt HH. Differential diagnosis between cerebral haemorrhage and cerebral thrombosis: a clinical and pathological study of 245 cases. Arch Intern Med 1935;56:435-56.

"Dalsgaard-Nielson T. Some clinical experience in the treatment of cerebral apoplexy (1000 cases). Acta Psychiatrica et Neurologica Scandinavica [Suppl]

12 Pickering G. High blood pressure. Edinburgh: Churchill Livingstone, 1968:337. Graham DI. Ischaemic brain damage of cerebral perfusion failure type following treatment of severe hypertihsion. A report of 2 cases. Br Med $\mathcal{F} 1979$;iv: $739-40$.
Anonymous. Dangerous antihypertension [Editorial]. Br Med $\mathcal{f} 1979$;ii :228-9.

(Accepted 2 May 1984) mortality from conditions amenable to medical intervention in England and

Breckenridge A, Dollery CT, Parry EMO. Prognosis of treated hypertension:

\section{SHORT REPORTS}

\section{Campylobacter infection mimicking Crohn's disease in an immuno- deficient patient}

Campylobacter jejuni is a common cause of infectious diarrhoea. Usually, it is a self limiting infection, causing abdominal pain and diarrhoea for two to three days. We describe a patient with immunodeficiency in whom campylobacter infection had a chronic course and rectal biopsy showed granuloma; the infection thus mimicked Crohn's disease.

\section{Case report}

A 51 year old married carpenter was admitted to hospital for investigation of diarrhoea. He had been well until the sudden onset of painless, watery diarrhoea four months previously. He had lost $6.4 \mathrm{~kg}$ in weight. On examination he was pale and thin and had a temperature of $37.5^{\circ} \mathrm{C}$. The liver was $3 \mathrm{~cm}$ enlarged, and the spleen was palpable $2 \mathrm{~cm}$ below the left costal margin. Rectal examination yielded normal results. At sigmoidoscopy the rectal mucosa looked normal but there was contact bleeding. A barium enema showed a featureless colon compatible with acute colitis. Rectal biopsy showed chronic inflammation with granuloma (figure). The histological appearances were consistent with Crohn's disease. Stool cultures grew Campylobacter spp. He was treated with erythromycin $500 \mathrm{mg}$ twice daily for one week. Subsequent stool cultures yielded negative results. His symptoms improved, he gained weight, and his fever settled. Six months later a repeat rectal biopsy specimen was normal.

During the investigation an anterior mediastinal mass was found on chest radiography. Haemoglobin concentration was $7 \cdot 3 \mathrm{~g} / \mathrm{dl}$, reticulocytes $1 \%$. White cell count was $7.8 \times 10^{9} / 1$ with a lymphocyte count of $4.8 \times$ $10^{9} / 1: 79 \%$ were T cells, of which $12 \%$ were OKT 4 and $88 \%$ OKT 8 , indicating a reversal of the normal helper to suppressor ratio. A bone marrow aspirate showed decreased normoblastic erythropoiesis, normal iron stores, and a high lymphocyte count $(25 \%)$. Immunoglobulin concentrations were reduced as follows: IgG 4.1 g/l (normal 8-18 g/l), IgA $0.3 \mathrm{~g} / 1$ (0.9$4.5 \mathrm{~g} / \mathrm{l})$, and $\mathrm{IgM} 0.6 \mathrm{~g} / 1(0 \cdot 6-2 \cdot 8 \mathrm{~g} / \mathrm{l})$. Anterior mediastinotomy was performed. A thymoma was removed, which was histologically of spindle cell type.

During follow up of one year the patient remained well with no recurrence of diarrhoea. The liver and spleen remained enlarged. The haemoglobin concentration returned to normal, but the lymphocytosis, abnormal lymphocyte subsets, and hypogammaglobulinaemia persisted.

\section{Comment}

Anaemia and hypogammaglobulinaemia associated with an excess of suppressor lymphocytes are well recognised as adjuncts of thymoma and may persist after thymectomy. ${ }^{1}$ Both recurrent and prolonged infections with $C$ jejuni have been reported in patients with hypogammaglobulinaemia. ${ }^{2} 3$

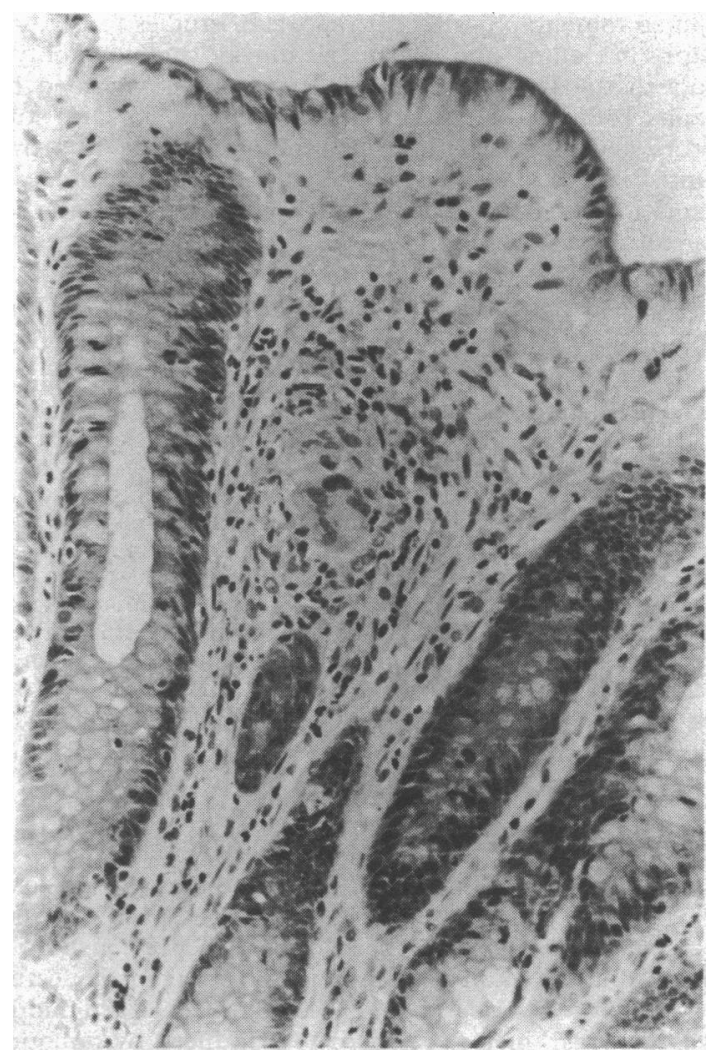

Giant cells in rectal biopsy specimen. Haematoxylin and eosin $\times 200$.

On rectal biopsy campylobacter colitis usually appears as a focal, non-specific colitis, although poorly formed granuloma have been disease was made. This was supported by the protracted course of the illness, weight loss, and anaemia. The prompt and sustained clinical response to treatment with erythromycin and the subsequent normal rectal biopsy appearances, however, militate against this diagnosis. We propose that the chronicity of the infection in this immunodeficient patient led to the formation of granuloma. The distinction between Crohn's disease and colitis due to campylobacter infection is important. Failure to recognise the unusual clinical and histological observed. ${ }^{4}$ In this patient a confident histological diagnosis of Crohn's 